\title{
Analisis Pengaruh Harmonisa terhadap Rugi-Rugi Daya pada Sistem Tegangan Rendah dan Transformator GR088 di Penyulang Menjangan
}

\author{
Salim Afif ${ }^{1}$, I W. Sukerayasa ${ }^{2}$, W. G. Ariastina ${ }^{3}$ \\ Program Studi Teknik Elektro, Fakultas Teknik, Universitas Udayana Denpasar - Bali \\ Email : salim.afif@pln.co.id ${ }^{1}$, sukerayasa@unud.ac.id ${ }^{2}$,w.ariastina@unud.ac.id ${ }^{3}$
}

\begin{abstract}
Abstrak
Penyulang Menjangan merupakan sistem jaringan tegangan menengah $20 \mathrm{kV}$ yang melayani daerah Gilimanuk dan sebagian Buleleng. Penyulang Menjangan memiliki total gardu terpasang sebanyak 69 buah, dimana Gardu GR088 adalah salah satu gardu yang menjadi penyumbang kandungan harmonisa arus $\left(T H D_{i}\right)$ tertinggi. Pada penelitian ini akan dikaji mengenai pengaruh harmonisa terhadap rugi-rugi daya pada sisi sistem tegangan rendah di gardu distribusi GR088 Penyulang Menjangan. Metode yang digunakan dalam penelitian ini adalah metode pengukuran harmonisa langsung pada masing-masing beban pelanggan tegangan rendah gardu distribusi GR088 di Penyulang Menjangan. Selanjutnya dilakukan simulasi analisis aliran daya harmonisa dengan menggunakan perangkat lunak yang tersedia. Rugi-rugi daya total pada Transformator dan Sistem Tegangan Rendah di GR088 Penyulang Menjangan kondisi tanpa harmonisa adalah sebesar 1481,7 Watt dan total rugi-rugi daya kondisi dengan kandungan harmonisa adalah sebesar 1552,5 Watt. Selisih antara rugi-rugi daya pada kondisi tanpa kandungan harmonisa dan rugi-rugi daya pada kondisi dengan kandungan hamonisa adalah sebesar 70,8 Watt. Dari kondisi tersebut selain dapat mempengaruhi kinerja transformator karena panas yang ditimbulkan harmonisa, potensi rugi-rugi daya yang terjadi akibat dampak pengaruh harmonisa tersebut yaitu sebesar 1,7 kWh per hari atau sekitar $620 \mathrm{kWh}$ setahun. Jika dikonversikan kedalam rupiah maka Gardu GR088 ikut menyumbangkan kerugian terhadap PT PLN (Persero) sebesar Rp.910.018,8 per tahunnya akibat harmonisa arus $\left(T H D_{i}\right)$.

Kata kunci : Kondisi tanpa Harmonisa, Kondisi dengan Harmonisa, Harmonic Analysis Load Flow, Rugi Daya, Sistem Tegangan Rendah
\end{abstract}

\begin{abstract}
Menjangan feeder is a medium-voltage network system which distributes electricity throughout Gilimanuk and some areas in Buleleng. It has 69 distribution substations, which one of them, substation GR088, contributes to the highest value of the total harmonic distortion $\left(T H D_{i}\right)$. In this research, the effect of harmonic distortions on losses at low voltage system of substation GR088 will be evaluated. The method used in this study is direct measurement of harmonic distortions at each low-voltage costumer whose electricity is generated by substation GR088 at Menjangan Feeder. Software is also used to perform harmonic load flow analysis and simulations. The total value of losses on transformer and low voltage system of substation GR088 Menjangan feeder, in a no-harmonic condition is 1481,7 Watt. On under-harmonic condition, the total value of losses is 1552,5 Watt. Therefore there is a 70,8 Watt difference between the two conditions. At this case, beside the heat created by the harmonic distortion that can affect the performance of transformers, it also cause a quite great value of losses, which is 1,7 kWh per day, or approximately $620 \mathrm{kWh}$ per year. It means the harmonic distortion in substation GR088 can cause PT PLN (Persero) lose Rp.910.018,8 per year. Keywords :No-Harmonic Condition, Under-Harmonic Condition, Harmonic Analysis Load Flow, Power Losses, Low-Voltage System
\end{abstract}

\section{PENDAHULUAN}

Harmonisa adalah gelombang tegangan atau arus sinusoidal yang memiliki frekuensi yang merupakan hasil kali integer dari frekuensi dasar dimana suplai sistem dirancang untuk beroperasi (biasanya 50 atau $60 \mathrm{~Hz}$ ). Pada dasarnya, harmonisa adalah gejala pembentukan gelombanggelombang dengan frekuensi berbeda yang merupakan perkalian bilangan bulat dengan frek- 
uensi dasarnya. Pada batas tertentu harmonisa kelipatan ganjil dapat berpengaruh buruk terhadap peralatan elektronika rumah tangga. Harmonisa juga dapat meningkatkan rugi daya pada sistem jaringan listrik. Harmonisa dapat meningkatkan rugi daya pada penyulang. Penelitian yang dilakukan oleh Wisnu pada penyulang Menjangan PT.PLN Persero Area Bali Utara dengan melakukan pengukuran $T H D_{i}$ pada semua trafo sisi tegangan rendah didapatkan bahwa trafo GR 88 mempunyai $T H D_{i}$ paling tinggi sebesar 24,70\%[1].

Penelitian ini akan dilanjutkan untuk menganalisis pada sisi tegangan rendah dengan mengukur $T H D_{i}$ pada semua pelanggan gardu GR088. Hasil ukur tersebut kemudian dilakukan simulasi menggunakan bantuan perangkat lunak sebagai analisis arus harmonisa pada sisi sistem tegangan rendah sehingga dapat dilakukan perhitungan rugi-rugi daya pada sistem tegangan rendah di Trafo Distribusi GR088.

\section{TINJAUAN PUSTAKA}

Berdasarkan Standar IEC (International Electrotechnical Commission) 1000.4-11, gangguan harmonisa tergolong kedalam Distorsi Bentuk Gelombang. Fenomena ini terjadi perubahan bentuk gelombang dari gelombang dasarnya [2].

Harmonisa disebabkan oleh adanya beban nonlinear yang digunakan dalam sistem tenaga listrik. Peralatan seperti converter, penyearah, adjusttable speed drive untuk mengendalikan motor-motor industri, thyristor controlled reactor, serta berbagai peralatan yang didasarkan pada proses pensaklaran dapat menyebabkan terjadinya harmonisa. Sedangkan untuk beban, yang dapat menimbulkan harmonisa antara lain electric arc furnace, induction furnace, serta mesin las, dimana beban tersebut berubah-ubah dari waktu ke waktu dengan cepat secara nonlinier [3]. Harmonisa yang ditimbulkan oleh peralatan yang digunakan menyebabkan perubahan pada bentuk gelombang.

\subsection{Harmonisa pada Jaringan Distribusi}

Sistem tenaga listrik dirancang untuk beroperasi pada frekuensi 50 atau $60 \mathrm{~Hz}$. Akan tetapi pada aplikasinya beberapa beban menyebabkan munculnya arus/tegangan yang frekuensinya merupakan kelipatan $50 / 60 \mathrm{~Hz}$ [4]. Seperti yang terlihat pada Gambar 1
Umumnya keberadaan harmonik ini membawa kerugian pada berbagai alat, salah satunya adalah transformator distribusi.

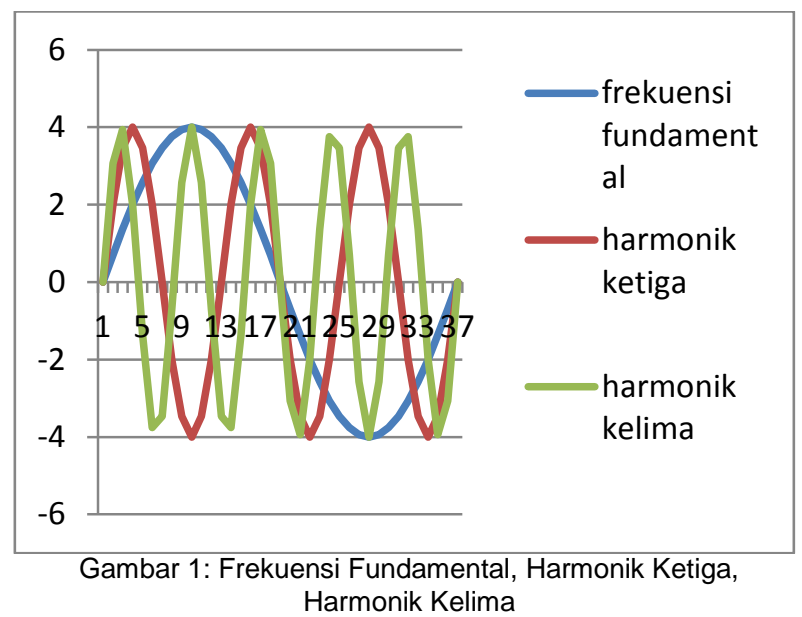

\subsection{Pengaruh Harmonisa}

Frekuensi harmonik yang lebih tinggi dari frekuensi kerjanya akan mengakibatkan penurunan efisiensi atau terjadi kerugian daya. Secara khusus, efek atau dampak jangka panjang yang ditimbulkan oleh harmonik pada sistem tenaga listrik sebagai berikut [4]:

- Pemanasan kapasitor

- Tegangan non-sinusoidal yang diterapkan pada mesin listrik dapat meningkatkan rugi inti dan rugi belitan, serta pemanasan lebih.

- Frekuensi harmonik yang lebih tinggi dari frek-uensi kerjanya akan mengakibatkan penurunan efisiensi dan pada akhirnya mengakibatkan ke-rugian daya pada transformator.

- Pemanasan pada kabel dan peralatan lainnya, rugi-rugi kabel yangdilewati oleh arus harmonik akan semakin besar.

\subsection{Rugi-Rugi pada Penghantar}

Rugi-rugi yang terjadi pada penghantar bergantung besar arus yang mengalir dan besar tahanan yang dimiliki penghantar tersebut. Dengan mengalirnya arus harmonisa $\left(I_{r m s}\right)$ pada penghantar, maka akan menyebabkan terjadinya penambahan panas sehingga terjadi peningkatan rugi-rugi $I^{2} R$ pada penghantar tersebut. Besarnya rugi-rugi penghantar $\left(P_{\text {Loss }}\right)$ dapat dihitung dengan Persamaan (1) akibat terdapatnya komponen harmonisa di dalam arus beban [5] : 
Keterangan :

$$
P_{\text {Loss }}=\sum_{n=1}^{\infty} I_{n}^{2} \cdot R_{n}
$$

$P_{\text {Loss }}$ adalah rugi-rugi penghantar (Watt)

$I_{n} \quad$ adalah arus komponen harmonisa (Ampere)

$R_{n} \quad$ adalah tahanan untuk frekuensi harmonik $(\mathrm{Ohm})$

\subsection{Rugi-Rugi pada Transformator}

Rugi-rugi transformator dikelompokkan menjadi rugi tanpa beban dan rugi berbeban (load losses). Rugi-rugi transformator keseluruhan dihitung melalui Persamaan (2) sebagai berikut [6].

$$
P_{T L}=P_{N L}+P_{L L}
$$

Keterangan :

$P_{T L}$ adalah rugi total transformator

$P_{N L}$ adalah rugi tanpa beban

$P_{L L}$ adalah rugi berbeban

\subsubsection{Rugi Transformator Tanpa Beban}

Susut trafo tanpa beban (beban nol) terdiri dari susut eddy current $\left(P_{E C}\right)$ dan susut hysterisis. Susut eddy current adalah besaran dari eddy current yang dihasilkan oleh tegangan induksi pada laminasi sebagai respon terhadap alternating flux yang merupakan proporsional dari kuadrat ketebalan laminasi, kuadrat dari frekuensi dan kuadrat dari nilai efektif $(r m s)$ kerapatan flux. Menurut IEEE Std C57.110-2008, susut tanpa beban tidak berpengaruh terhadap arus harmonisa [8].

\subsubsection{Rugi Transformator Berbeban}

Perhitungan yang digunankan untuk rugi-rugi transformator pada ratingnya dalam per-unit (pu) dihitung dengan Persamaan (3).

$$
\begin{aligned}
& P_{L L-R}(p u)=1+P_{E C-R}(p u)+P_{O S L-R}(p u) \\
& \text { Keterangan : } \\
& P_{L L-R} \text { adalah rugi berbeban pada rating } \\
& \text { transformator. }
\end{aligned}
$$

Untuk menghitung kemampuan transformator menggunakan data desain, mengacu kepada IEEE Std C57.12.90-1993 [6] dan IEEE Std. C57. 12.91-1995 [7], maka rugi transformator karena mengalirnya arus beban melalui belitan transformator.
Rugi Ohmik $\left(I^{2} R\right)$, akibat arus beban mengalir pada konduktor atau belitan dan ini disebut "Rugi $d c$ " dihitung dengan Persamaan (4).

$$
P_{I R-R}^{2}=K \cdot\left[\left(I_{1-R}\right)^{2} \cdot R_{1}\right]+\left[\left(I_{2-R}\right)^{2} \cdot R_{2}\right] \text { Watt }
$$

Keterangan:

$$
\begin{array}{ll}
P_{I R-R}^{2} & \begin{array}{l}
\text { adalah rugi Ohmik pada rating } \\
\text { transformator. }
\end{array} \\
K & \begin{array}{l}
\text { adalah } 1.5 \text { untuk transformator tiga } \\
\text { phasa. }
\end{array} \\
I_{1-R} . & \begin{array}{l}
\text { adalah rating arus pada sisi tegangan } \\
\text { tinggi primer. }
\end{array} \\
I_{2-R} & \begin{array}{l}
\text { adalah rating arus pada sisi tegangan } \\
\text { rendah sekunder. }
\end{array} \\
R_{1} & \begin{array}{l}
\text { adalah nilai resistansi (3 phasa) pada } \\
\text { sisi tegangan tinggi. }
\end{array} \\
R_{2} & \begin{array}{l}
\text { adalah nilai resistansi (3 phasa) pada } \\
\text { sisi tegangan rendah. }
\end{array}
\end{array}
$$

Rugi Sasar/Stray Losses $\left(P_{T S L-R}\right)$ merupakan rugi-rugi transformator berbeban $\left(P_{L L-R}\right)$ dikurangi Rugi Ohmik atau Rugi dc $\left(P_{I R-R}^{2}\right)$ seperti Persamaan (5).

$P_{T S L-R}=P_{L L-R}-\left\{K \cdot\left[\left(I_{1-R}\right)^{2} \cdot R_{1}\right]+\left[\left(I_{2-R}\right)^{2} \cdot R_{2}\right]\right\}$ Watt

Keterangan :
$K \quad$ adalah 1.5 untuk transformator tiga phasa
$P_{T S L-R}$ adalah rugi sasar total sesuai rating
$P_{L L-R}$ adalah rugi berbeban sesuai rating
$R_{1} \quad$ adalah nilai resistansi (3 phasa pada sisi tegangan tinggi
$R_{2} \quad$ adalah nilai resistansi (3 phasa) pada sisi tegangan rendah
$I_{1-R}$ adalah rating arus pada sisi tegangan tinggi primer
$I_{2-R} \quad$ adalah rating arus pada sisi tegangan rendah sekunder

Asusmsi yang digunakan IEEE Std C57.1101998 untuk tipe transformator dengan pendingin minyak [8], untuk mendapatkan rugi arus eddy $\left(P_{E C-R}\right)$ adalah dengan Persamaan (6).

$$
P_{E C-R}=P_{T S L-R} \times 0.33 \mathrm{Watt}
$$

Rugi sasar lain $\left(P_{O S L}\right)$ pada inti dan metal serta dinding transformator akibat terpotongnya fluks sasar dihitung dengan Persamaan (7).

Keterangan :

$$
P_{O S L-R}=P_{T S L-R}-P_{E C-R} \text { Watt }
$$

$P_{O S L-R}$ adalah rugi sasar lain sesuai ratingnya

$P_{T S L-R}$ adalah rugi sasar total sesuai ratingnya

$P_{E C-R}$ adalah rugi arus eddy sesuai ratingnya

Faktor harmonisa arus eddy belitan didapatkan dengan Persamaan (8). 


$$
F_{H L}=\left(\sum_{n=1}^{\operatorname{mak}}\left(\frac{I_{n}}{I}\right)^{2} n^{2}\right) /\left(\sum_{n=1}^{\operatorname{mak}}\left(\frac{I_{n}}{I}\right)^{2}\right)
$$

Keterangan :

$F_{H L}$ adalah faktor harmonisa untuk rugi arus eddy belitan.

$n$ adalah harmonisa orde ke-n

$I_{n}$ adalah arus dengan komponen harmonisa ke-n

$I_{1}$ adalah arus beban fundamental (Ampere)

Faktor harmonisa untuk rugi sasar lain diperoleh dengan Persamaan (9).

$$
F_{H L-S T R}=\left(\sum_{n=1}^{\operatorname{mak}}\left(\frac{I_{n}}{I_{1}}\right)^{2} \cdot h^{0.8}\right) /\left(\sum_{n=1}^{\operatorname{mak}}\left(\frac{I_{n}}{I_{1}}\right)^{2}\right)
$$

Keterangan :

$F_{H L-S T R}$ adalah Faktor harmonisa untuk rugi sasar lain

$n$ adalah Harmonisa orde ke-n

$I_{n}$ adalah Arus dengan komponen harmonisa ke-n

$I_{1}$ adalah Arus beban fundamental (ampere)

Rugi transformator berbeban dengan adanya harmonisa dihitung dengan Persamaan (10).

$$
\begin{aligned}
& P_{L L}(p u)=P_{I R-n}^{2}+\left[\left(F_{H L} \times P_{E C}\right)+\left(F_{H L-S T R} \times P_{O S L}\right)\right](10) \\
& \text { Keterangan : }
\end{aligned}
$$

\section{METODE PENELITIAN}

Penelitian ini dilakukan di sisi tegangan rendah dimasing-masing pelanggan pada Trafo Distribusi GR 088. Data yang digunakan dalam penelitian ini merupakan data yang diperoleh dengan pengukuran secara langsung berupa Arus (I), Tegangan (V), Total Harmonic Distortion arus $\left(T H D_{i}\right)$, dan Cos phi yang diukur pada sumber utama ( $L V$ Board) dan masing-masing pelanggan (kWh Meter) yang dilayani oleh Gardu GR 088 di Penyulang Menjangan, dengan total pelanggan (8yaitu sebanyak 188. Waktu pengukuran dilakukan mulai jam $9.00-16.00$.

Hasil data pengukuran tersebut akan dilakukan simulasi harmonic analysis menggunakan bantuan perangkat lunak. Hasil simulasi akan diperoleh arus fundamental dan arus r.m.s yang digunakan dalam perhitungan rugi-rugi daya sistem yang terpolusi harmonik. Juga dilakukan analisis rugi daya sisten tanpa terpolusi harmonik, sehingga bisa dilakukan perbandingan dari kedua hasil tersebut.

\section{PEMBAHASAN}

\subsection{Gambaran Umum GR088}

Gardu distribusi GR088 memiliki kapasitas sebesar 100 KVA dengan tipe konstruksi gardu 2 tiang dan memiliki 2 jurusan yang menyuplai listrik ke daerah Gilimanuk tepatnya dikawasan jalan Sumber Kelampok. Gardu distribusi GR088 menyuplai daya untuk188 pelanggan mayoritas rumah tangga, berikut rincian pelanggan di gardu GR088 [9]:

1. Rumah tangga sebanyak 175 pelanggan.

2. Sosial (rumah ibadah, banjar, dII) sebanyak 6 pelanggan.

3. Bisnis sebanyak 4 pelanggan, dan

4. Pemerintahan sebanyak 3 pelanggan.

\subsection{Data Hasil Pengukuran THD Trafo dan Pelanggan GR088}

Data hasil pengukuran THD transformator GR 088 di Penyulang Menjangan dan seluruh pelanggan terpasang pada saluran di gardu GR088 dapat dilihat pada Tabel 1 dan Tabel 2 .

adalah faktor susut akibat arus harmo

Tabel 1. Data Hasil Pengukuran THD Trafo GR088

\begin{tabular}{|c|c|c|c|}
\hline \multirow{2}{*}{$\begin{array}{c}\text { Harmonisa } \\
\text { (\%) }\end{array}$} & \multicolumn{3}{|c|}{$\begin{array}{c}\text { GR088 } \\
\text { (100 kVA) }\end{array}$} \\
\cline { 2 - 4 } & $\mathbf{R}$ & $\mathbf{S}$ & $\mathbf{T}$ \\
\cline { 2 - 4 } & 27,56 & 24,70 & 23,60 \\
\hline$T H D_{i}$ & 21,9 & 20,4 & 19,5 \\
\hline $\mathrm{n}=3$ & 12,3 & 12,6 & 10,3 \\
\hline $\mathrm{n}=5$ & 8,0 & 7,8 & 7,7 \\
\hline $\mathrm{n}=7$ & 6,9 & 3,6 & 6,0 \\
\hline $\mathrm{n}=9$ & 3,8 & 0,6 & 2,8 \\
\hline $\mathrm{n}=11$ & 0,9 & 1,2 & 0,2 \\
\hline $\mathrm{n}=13$ & 1 & 0,9 & 1,2 \\
\hline $\mathrm{n}=15$ & 0,7 & 0,5 & 0,3 \\
\hline $\mathrm{n}=17$ & 0,3 & 0,6 & 0,8 \\
\hline $\mathrm{n}=19$ & & & \\
\hline
\end{tabular}

Tabel 2. Data Beban Pelanggan 


\begin{tabular}{|c|c|c|}
\hline No & $\begin{array}{c}\text { Daya Tarif } \\
\text { (VA) }\end{array}$ & $\begin{array}{c}\text { Jumlah } \\
\text { (Pelanggan) }\end{array}$ \\
\hline $\mathbf{1}$ & 450 & 56 \\
\hline $\mathbf{2}$ & 900 & 95 \\
\hline $\mathbf{3}$ & 1300 & 25 \\
\hline $\mathbf{4}$ & 2200 & 10 \\
\hline $\mathbf{5}$ & 3500 & 2 \\
\hline \multicolumn{2}{|c|}{ Total Jumlah Pelanggan } & $\mathbf{1 8 8}$ \\
\hline
\end{tabular}

Berdasarkan Peraturan Menteri Energi Dan Sumber Daya Mineral Nomor : 04 Tahun 2009 tentang batas maksimum distorsi harmonisa arus dalam persyaratan sistem teknik distribusi pada rentang orde harmonic $\mathrm{h}<11$ adalah $4 \%$ [10] Data hasil pengukuran pada pelanggan yang dilayani oleh Gardu GR088 dapat dideskripsikan sebagai berikut:

1. Pengukuran $T H D_{i}$ dilakukan langsung pada 188 pelanggan yang dilayani oleh Gardu GR088
2. Berdasarkan hasil pengukuran didapatkan 135 Jumlah Pelanggan $(71,8 \%)$ yang melampaui batas maksimum distorsi harmonisa arus sesuai standar Peraturan Menteri ESDM no.04 thn 2009.

3. Jumlah pelanggan yang berada dibawah batas maksimum distorsi harmonisa arus adalah 53 pelanggan $(28,2 \%)$.

\subsection{Analisis Arus Fundamental dan Arus} rms

Langkah awal yang dilakukan adalah dengan membuat model sistem jaringan tegangan rendah dimana trafo GR088 sebagai power grid, sélanjutnya input data - data yang diperlukan untuk running program. Hasil analisis adalah berupa arus fundamental yang selanjutnya digunakan dalam perhitungan rugi-rugi daya penghantar tảnpa harmonisa dan arus rms yang digunakan dalam …perhitungan... fugi-fugi...daya $\cdots$...penghantar dengan harmonisa. 


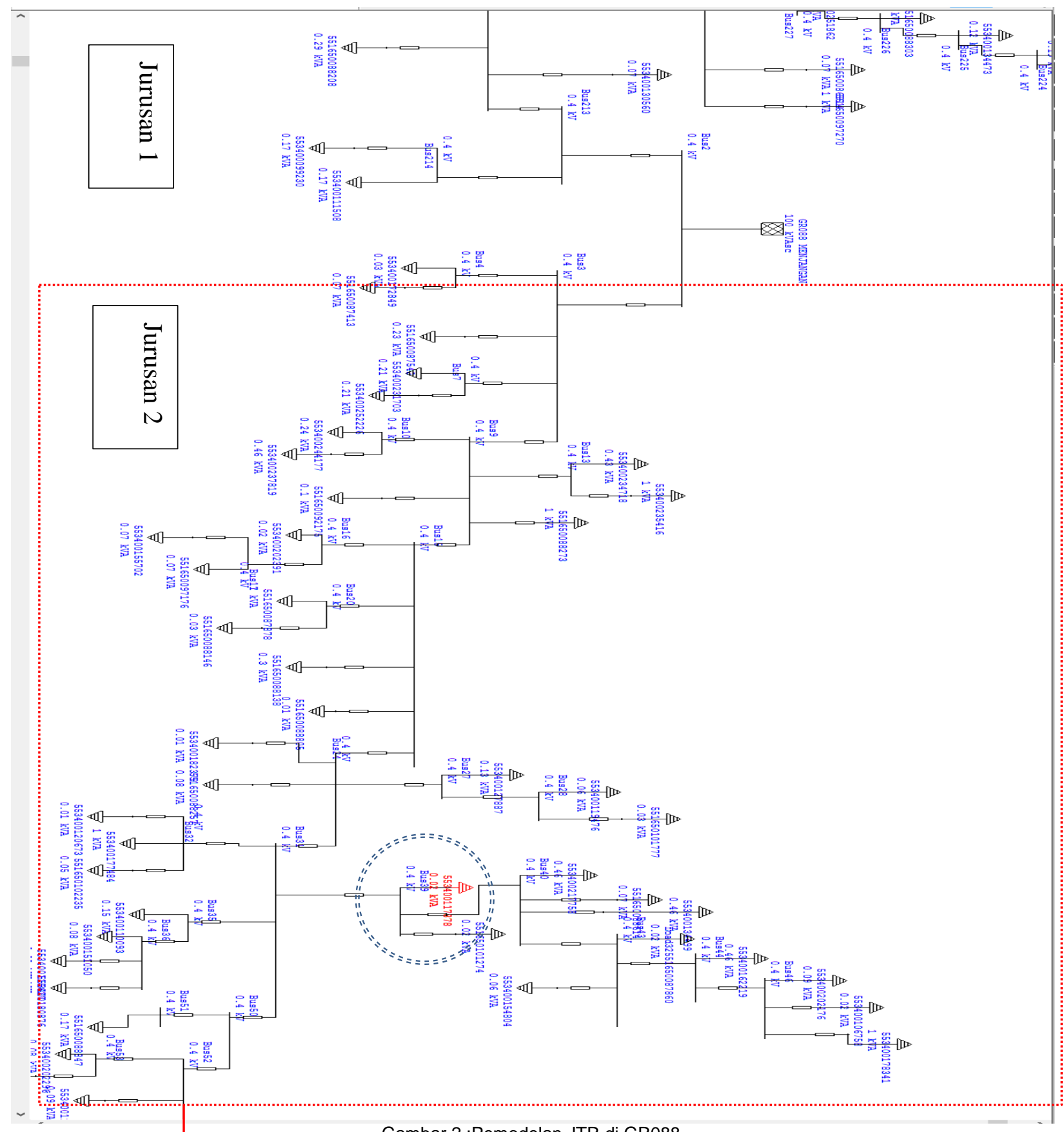

Gambar 2 :Pemodelan JTR di GR088

Setelah dilak凶kan running program ak menghasilkan arus fundamental dan arus rnæso dengan nilai arus tertinggi terdapat pada line di cable 2 seperti pada Tabel 3.

Tabel 3. Data Hasil Simulasi THD total Pelanggan

\begin{tabular}{|c|c|c|c|c|c|c|c|c|}
\hline n & \multirow{2}{*}{ Id Line } & \multicolumn{3}{|c|}{ Arus fundamental (A) } & \multicolumn{3}{|c|}{ Arus $r m s(A)$} & \multirow{2}{*}{ phasa } \\
\hline di & & $\mathbf{R}$ & $\mathbf{s}$ & T & $\mathbf{R}$ & $\mathbf{s}$ & $T$ & \\
\hline 1 & Cable 2 & 45.18 & 45.18 & 45.18 & 45.318 & 45.318 & 45.32 & 3 \\
\hline 2 & Cable160 & & 21.224 & & & 21.693 & & 1 \\
\hline
\end{tabular}




\subsection{Perhitungan Rugi-Rugi Penghantar Kondisi Tanpa Kandungan Harmo- nisa}

Rugi-rugi yang terjadi pada saluran/penghantar bergantung terhadap besar arus yang mengalir padanya dan besar tahanan yang dimiliki saluran tersebut, dimana pada kondisi tanpa harmonisa arus yang mengalir adalah arus fundamental.

Rugi - rugi daya tiga phasa pada saluran Cable-2 kondisi tanpa harmonisa dapat dihitung dengan Persamaan (1).

$$
\begin{aligned}
& I \text { (arus fundamental) }=45,181 \mathrm{~A} \text {. } \\
& L \text { (panjang penghantar) }=52 \mathrm{~m}=0,052 \mathrm{~km} \text {. } \\
& R \text { (Tahanan) } \quad=0,5096 \Omega / \mathrm{km} \text {. } \\
& L \quad=0,052 \mathrm{~km} \rightarrow R=0,0265 \Omega \text {. } \\
& \Delta P=3 \times(45,181)^{2} \times 0,0265 \\
& =162,285 \mathrm{Watt}
\end{aligned}
$$

Rugi - rugi daya satu phasa pada saluran Cable-160 kondisi tanpa harmonisa juga dapat dihitung dengan Persamaan (1).

$$
\begin{aligned}
& I \text { (arus fundamental) }=21,224 \mathrm{~A} . \\
& L \text { (panjang penghantar) }=14 \mathrm{~m}=0,014 \mathrm{~km} \text {. } \\
& R \text { (Tahanan) } \quad=3,5539 \Omega / \mathrm{km} \text {. } \\
& L \quad=0,014 \mathrm{~km} \rightarrow R=0,0498 \Omega \text {. } \\
& \Delta P=(21,224)^{2} \times 0,0498 \\
& =22,433 \mathrm{Watt}
\end{aligned}
$$

Berdasarkan hasil perhitungan di atas diketahui rugi-rugi daya daya tiga phasa pada saluran Cable-2 yaitu sebesar 162,285 Watt dan rugi-rugi daya satu phasa pada saluran Cable160 yaitu sebesar 22,433 Watt. Dengan cara perhitungan yang sama seperti di atas, dapat dianalisis untuk masing-masing saluran yang memiliki nilai arus fundamental yang berbeda. Dari hasil perhitungan diperoleh rugi-rugi daya pada saluran tegangan rendah pada gardu GR088 sebesar 1080,743 Watt.

\subsection{Perhitungan Rugi-Rugi Transforma- tor Kondisi Tanpa Kandungan Har- monisa}

Harmonisa arus orde pertama (fundamental) akan digunakan dalam perhitungan rugi daya kondisi tanpa harmonisa seperti contoh sebagai berikut.
Diketahui data Transformator (GR088 100 kVA) sesuai rating adalah sebagai berikut :

$$
\begin{array}{ll}
\text { Rugi tanpa beban }\left(P_{N L}\right) & =210 \mathrm{Watt} \\
\text { Rugi berbeban }\left(P_{L L}\right) & =1420 \mathrm{Watt} \\
\text { Resistan sisi primer }\left(R_{1}\right) & =182 \Omega \\
\text { Arus sisi primer }\left(I_{1}\right) & =2.89 \mathrm{Amp} \\
\text { Resistan sisi primer }\left(R_{2}\right) & =0.0027 \Omega \\
\text { Arus sisi primer }\left(I_{2}\right) & =151.94 \mathrm{Amp}
\end{array}
$$

Melalui Persamaan (5),(6), dan (7), data di atas dapat dihitung total rugi sasar sesuai rating transformator sebagai berikut :

$$
\begin{aligned}
P_{T S L-R}= & 1420-\left\{1,5 \times\left[(2,89)^{2} \times 0,182\right]\right. \\
& \left.+\left[(151.94)^{2} \times 0,0027\right]\right\} \\
= & 1324,222534 \mathrm{Watt} \\
P_{E C-R}= & 1324,222534 \times 0.33 \\
= & 436,993436 \mathrm{Watt} \\
P_{O S L-R}= & 1324,222534-436,9934360 \\
= & 887,2291 \mathrm{Watt} \\
1420 & =P_{I R-R}^{2}+436,993436+887,2291 \\
P_{I R-R}^{2} & =95,777 \mathrm{Watt}
\end{aligned}
$$

Tabel 4. Perhitungan Faktor Rugi Harmonisa Trasformator Gr088 Penyulang Menjangan Dalam ( $P u$ K Kondisi Tanpa Kandungan Harmonisa

\begin{tabular}{|c|c|c|c|c|c|c|}
\hline $\begin{array}{c}\text { Orde } \\
(\mathbf{n})\end{array}$ & $\left(\operatorname{In} / 1_{1}\right)$ & $\left(\operatorname{In} / 1_{1}\right)^{2}$ & $\left(\mathbf{n}^{2}\right)$ & $\left(\operatorname{In} / 1_{1}\right)^{2 *} \mathbf{n}^{2}$ & $\left(\mathbf{n}^{0.8}\right)$ & $\left(\operatorname{In} / \mathbf{l}_{1}\right)^{2 *} \mathbf{n}^{0.8}$ \\
\hline 1 & 1,000 & 1,000 & 1 & 1,000 & 1,000 & 1,000 \\
\hline
\end{tabular}

Dari Tabel 4 didapatkan $F_{H L}$ dan $F_{H L-S T R}$ sesuai Persamaan (8) dan (9) sebagai berikut :

$$
\begin{gathered}
F_{H L}=1,000 / 1,000=1,000 \mathrm{pu} \\
F_{H L-S T R}=1,000 / 1,000=1,000 \mathrm{pu}
\end{gathered}
$$

Jenis transformator yang dibahas dalam penelitian ini adalah transformator yang menggunakan minyak, beban transformator GR88 tercatat 36,67 \% dari kapasitasnya sehingga persamaan yang digunakan dalam perhitungan untuk menentukan maksimum arus yang dibebankan pada transformator adalah :

$$
\begin{gathered}
I_{\max }(p u) \\
=\sqrt{\frac{P_{L L-R}(p u)}{1+\left[F_{H L} \times P_{E C-R}(p u)\right]+\left[F_{H L-S T R} \times P_{O S L-R}(p u)\right]}} \\
0,3667=\frac{\sqrt{P_{L L}}}{\sqrt{1,000}} \\
(0,3667)^{2} \times(1,000)^{2}=P_{L L} \\
P_{L L}=0,134469(p u)
\end{gathered}
$$


Tabel 5. Hasil Perhitungan Rugi-Rugi Daya Transformator Gr088 Penyulang Menjangan Dalam Kondisi Tanpa Kandungan Harmonisa

\begin{tabular}{|c|c|c|c|c|}
\hline $\begin{array}{c}\text { Type } \\
\text { Rugi- } \\
\text { Rugi }\end{array}$ & $\begin{array}{c}\text { Rugi } \\
\text { sesuai } \\
\text { Rating } \\
\text { (Watt) }\end{array}$ & $\begin{array}{c}\text { Rugi } \\
\text { sesuai } \\
\text { Beban } \\
\text { Trafo } \\
\text { (Watt) }\end{array}$ & $\begin{array}{c}\text { Faktor } \\
\text { Harmonisa } \\
\text { (pu) }\end{array}$ & $\begin{array}{c}\text { Koreksi } \\
\text { Rugi- } \\
\text { Rugi } \\
\text { (Watt) }\end{array}$ \\
\hline $\begin{array}{c}\text { Tidak } \\
\text { berbeban }\end{array}$ & 210 & 210 & 210 \\
\hline $\begin{array}{c}\text { Rugi } \\
\text { Ohmik } \\
\text { (I'R) }\end{array}$ & 95,78 & 12,879 & 1,000 & 58,762 \\
\hline $\begin{array}{c}\text { Rugi arus } \\
\text { eddy }\end{array}$ & 436,99 & 58,762 & 1,000 & 119,305 \\
\hline $\begin{array}{c}\text { Rugi } \\
\text { Sasar } \\
\text { Lain }\end{array}$ & 887,23 & 119,305 & & $\mathbf{4 0 0 , 9 4 6}$ \\
\hline $\begin{array}{c}\text { Rugi } \\
\text { Total }\end{array}$ & & & & \\
\hline
\end{tabular}

Berdasarkan hasil perhitungan pada Tabel 5 diketahui rugi-rugi daya total transformator GR088 sesuai beban transformator dalam kondisi tanpa harmonisa yaitu sebesar 400,946 Watt.

\subsection{Perhitungan Rugi-Rugi Penghantar Kondisi Dengan Kandungan Harmo- nisa}

Perhitungan rugi-rugi daya saluran dengan kandungan harmonisa, dimana In yang dipakai adalah arus rms hasil simulasi. Sebagai contoh perhitungan rugi - rugi daya tiga phasa pada saluran cable-2 kondisi dengan harmonisa sesuai Persamaan (1).

$$
\begin{aligned}
& I_{r m s}(\text { Arus harmonisa })=45.318 \mathrm{~A} . \\
& L \quad \text { (Panjang penghantar })=52 \mathrm{~m}=0,52 \mathrm{~km} . \\
& R \quad(\text { Tahanan })=0.5096 \Omega / \mathrm{km} . \\
& \begin{aligned}
& L=0,52 \mathrm{~km} \rightarrow R=0.026 \Omega \\
& P_{\text {Loss }}=3 \times(45,318)^{2} \times 0.0265 \\
&=163,271 \mathrm{Watt}
\end{aligned}
\end{aligned}
$$

Sedangkan untuk rugi - rugi daya satu phasa pada saluran Cable-160 kondisi dengan harmonisa dihitung dengan Persamaan (1):

$$
\begin{aligned}
& I \quad \text { (arus fundamental) }=21,693 \mathrm{~A} . \\
& L \quad \text { (panjang penghantar })=14 \mathrm{~m}=0,014 \mathrm{~km} . \\
& R(\text { Tahanan })=3,5539 \Omega / \mathrm{km} . \\
& \begin{aligned}
L=0,014 \mathrm{~km} \rightarrow R=0,0498 \Omega \\
\Delta P \quad=(21,693)^{2} \times 0,0498
\end{aligned}
\end{aligned}
$$

$$
=23,435 \mathrm{Watt}
$$

Berdasarkan hasil perhitungan di atas diketahui rugi-rugi daya pada saluran tiga phasa di cable-2 tegangan rendah yaitu sebesar 163,271 Watt dan saluran satu phasa di cable-160 sebesar 23,435 Watt. Dengan cara perhitungan yang sama seperti di atas, dapat dianalisis untuk masing - masing saluran yang memiliki nilai arus $\mathrm{rms}\left(\mathrm{I}_{\mathrm{rms}}\right)$ yang berbeda sehingga total rugi-rugi daya pada jaringan tegangan rendah dengan harmonisa adalah sebesar 1097,010 Watt.

\subsection{Perhitungan Rugi-Rugi Transfor- mator Dengan Harmonisa}

Salah satu dampak yang umum dari pengaruh harmonisa adalah timbulnya panas yang lebih pada transformator serta terjadinya penurunan kapasitas. Frekuensi harmonisa yang lebih tinggi dari frekuensi kerjanya akan mengakibatkan penurunan efisiensi atau terjadi kerugian daya.

Sesuai dengan standar internasional (IEEE

\begin{tabular}{|c|c|c|c|c|c|c|}
\hline $\begin{array}{c}\text { Orde } \\
\text { (n) }\end{array}$ & $\left(\ln / I_{1}\right)$ & $\left(\ln / I_{1}\right)^{2}$ & $\left(n^{2}\right)$ & $\left(\ln / I_{1}\right)^{2 *} n^{2}$ & $\left(n^{0.8}\right)$ & $\left(\ln / l_{1}\right)^{2 *} n^{0.8}$ \\
\hline 1 & 1,000 & 1,000000 & 1 & 1,000000 & 1,0000 & 1,000000 \\
\hline 5 & 0,126 & 0,015876 & 25 & 0,396900 & 3,6239 & 0,057533 \\
\hline 7 & 0,078 & 0,006084 & 49 & 0,298116 & 4,74328 & 0,028858 \\
\hline 11 & 0,006 & 0,000036 & 121 & 0,004356 & 6,80948 & 0,000245 \\
\hline 13 & 0,012 & 0,000144 & 169 & 0,024336 & 7,78314 & 0,001121 \\
\hline 17 & 0,005 & 0,000025 & 289 & 0,007225 & 9,64626 & 0,000241 \\
\hline 19 & 0,006 & 0,000036 & 361 & 0,012996 & 10,5439 & 0,000380 \\
\hline
\end{tabular}
Std C57.110 ${ }^{\mathrm{TM}}-2008$ ) [10], dalam perhitungan pengaruh harmonisa untuk harmonisa kelipatan 3 seperti 3,6,9,12,15 dan seterusnya tidak dimasukkan dalam perhitungan, karena hanya berpengaruh pada besarnya ukuran luas penampang konduktor pada titik netral. Dalam perhitungan rugi-rugi daya pada Trafo GR088 dengan kapasitas trafo adalah 100 kVA sebagai berikut.

Tabel 6. Perhitungan Faktor Rugi Harmonisa Trasformator Gr088 Penyulang Menjangan Dalam (Pu) Kondisi Dengan 


\begin{tabular}{|l|l|l|l|l|l|l|}
\hline Total & & 1,022201 & & 1,743929 & & 1,088378 \\
\hline
\end{tabular}

Dari Tabel 6 didapatkan $F_{H L}$ dan $F_{H L-S T R}$ sesuai Persamaan (8) dan (9) sebagai berikut :

$F_{H L}=1,743929 / 1,022201=1,706053 p u$

$F_{H L-S T R}=1,088378 / 1,022201=1,06474 p u$

Beban transformator GR88 tercatat $36,67 \%$ dari kapasitasnya sehingga :

$$
\begin{gathered}
I_{\max }(p u) \\
=\sqrt{\frac{P_{L L-R}(p u)}{1+\left[F_{H L} x P_{E C-R}(p u)\right]+\left[F_{H L-S T R} \times P_{O S L-R}(p u)\right]}} \\
0,3667=\sqrt{P_{L L}} / \sqrt{1,022201} \\
P_{L L}=0,137454(p u)
\end{gathered}
$$

Tabel 7. Hasil Perhitungan Rugi-Rugi Daya Transformator Gr088 Penyulang Menjangan Dalam Kondisi Dengan Kandungan Harmonisa

\begin{tabular}{|c|c|c|c|c|}
\hline $\begin{array}{c}\text { Type Rugi- } \\
\text { Rugi }\end{array}$ & $\begin{array}{c}\text { Rugi } \\
\text { sesuai } \\
\text { Rating } \\
\text { (Watt) }\end{array}$ & $\begin{array}{c}\text { Rugi } \\
\text { sesuai } \\
\text { Beban } \\
\text { Trafo } \\
\text { (Watt) }\end{array}$ & $\begin{array}{c}\text { Faktor } \\
\text { Harmonisa } \\
\text { (Watt) }\end{array}$ & $\begin{array}{c}\text { Koreksi } \\
\text { Rugi- } \\
\text { Rugi } \\
\text { (Watt) }\end{array}$ \\
\hline $\begin{array}{c}\text { Tidak } \\
\text { berbeban }\end{array}$ & 210 & 210 & 210 \\
\hline $\begin{array}{c}\text { Rugi } \\
\text { Ohmik } \\
\text { (I }{ }^{2} \text { R) }\end{array}$ & 95,777 & 13,165 & & 13,165 \\
\hline $\begin{array}{c}\text { Rugi arus } \\
\text { eddy }\end{array}$ & 436,99 & 60,067 & 1,706053 & 102,4768 \\
\hline $\begin{array}{c}\text { Rugi Sasar } \\
\text { Lain }\end{array}$ & 887,2291 & 121,953 & 1,06474 & 129,849 \\
\hline \multicolumn{5}{|c|}{ Rugi Total } \\
\hline
\end{tabular}

\subsection{Perbandingan Hasil Perhitungan Rugi-Rugi Daya Total pada Sis- tem Tegangan Rendah dan Gardu GR088}

Hasil perhitungan kedua kondisi baik tanpa harmonisa maupun dengan harmonisa diketahui total rugi-rugi daya di Tegangan Rendah dan Transformator GR088 kondisi tanpa harmonisa adalah sebesar1481,689 Watt dan total rugirugi daya kondisi dengan kandungan harmonisa adalah sebesar 1552,5Watt. Selisih rugi - rugi daya adalah sebesar (rugi dengan harmonisa rugi tanpa harmonisa) $=1552,5-1481,689=$ 70,811 Watt.

Tabel 8. Perbandingan Rugi - Rugi Daya Di Jaringan Tegangan Rendah Dan Transformator Gr088

\begin{tabular}{|c|c|c|c|}
\hline Kondisi & $\begin{array}{c}\text { Rugi } \\
\text { Saluran } \\
\text { (W) }\end{array}$ & $\begin{array}{c}\text { Rugi } \\
\text { Transformator } \\
\text { (W) }\end{array}$ & $\begin{array}{c}\text { Rugi - rugi } \\
\text { Daya Total } \\
\text { (W) }\end{array}$ \\
\hline $\begin{array}{c}\text { Tanpa } \\
\text { Harmonisa }\end{array}$ & 1080,743 & 400,946 & 1481,689 \\
\hline Harmonisa & 1097,010 & 455,490 & 1552,5 \\
\hline
\end{tabular}

Dari hasil selisih diatas dapat dikonversikan kedalam satuan energi untuk mengetahui energi yang hilang akibat harmonisa yang timbul di gardu GR088 dan Jaringan Tegangan Rendah tersebut. Jika diasumsikan bahwa rugi-rugi daya adalah sama setiap saat maka dapat dilakukan perhitungan sebagai berikut :

Selisih Rugi harmonisa $=70,811$ Watt $=$ $0,0708 \mathrm{KW}$

1 hari $=24$ jam

$0,0708 \times 24=1,6992 \mathrm{KWH}$

Dengan harga energy listrik saat ini adalah sebesar Rp.1467,28 maka dapat dihitung kerugian akibat harmonisa pertahun sebagai berikut :

kerugian/tahun $=(1,6992 \times$ Rp. 1467,28$) \times$ $365=$ Rp. $910.018,79$

Dengan menggunakan asumsi tersebut maka dapat dikatakan bahwa harmonisa di tegangan rendah dan Gardu GR088 ikut menyumbangkan kerugian terhadap PT PLN (Persero) sebesar 910.018,79 Rupiah per tahunnya.

\section{KESIMPULAN}

Hasil pengukuran yang dilakukan pada 188 pelanggan yang dilayani oleh Gardu GR088 terdapat $71,8 \%$ pelanggan yang memiliki THDi melebihi standar batas maksimum distorsi harmonisa arus sesuai standar Peraturan Menteri ESDM no.04 thn 2009. Dengan $T H D_{\mathrm{i}}$ tertinggi mencapai $114,4 \%$ pada orde ke-3 yang terdapat pada pelanggan dengan ID: 553400117378. Sesuai dengan gambar jaringan yang sudah ditampilkan diatas dapat dikatakan bahwa salah satu penyebab harmonisa tertinggi di ID 553400117378 adalah karena beban tersebut terdapat dipangkal jaringan dimana kabel SR yang dihubungkan ke pelanggan dihubungkan kembali ke masing-masing beban yang berada di ekor jaringan. Sehingga bisa dikatakan beban harmonisa yang timbul di 
pelanggan tersebut adalah penjumlahan dari beban yang berada di ekor sampai pada beban yang diukur.

Dari analisis diperoleh pada sistem tegangan rendah dan transformator distribusi harmonik tidak berpengaruh signifikan terhadap peningkatan rugi-rugi daya. Potensi kerugian pada transformator GR88 dan sistem tegangan rendahnya akibat harmonisa yang dikonversi dalam rupiah adalah sebesar Rp.910.018,79 per tahun.

\section{DAFTAR PUSTAKA}

[1] Wisnu, Studi Analisis Pengaruh Harmonisa Terhadap Rugi-Rugi Daya Pada Penyulang Menjangan. Jurnal Teknologi Elektro. Vol. 16(1). Januari-April 2017.

[2] International Electrotechnical Commision (IEC) 6100-2-11990, Electromagnetic Compatibility. 1990.

[3] Dugan, Rizy. Harmonic Considerations for Electrical Distribution Feeder. National Technical Information Service. Report No. ORNL/Sub/81-95011/4 (Cooper Power Systems as Bulletin 87011. 2001.

[4] Syahwil, M, Tola M, Manjang M. Studi Dampak Harmonisa Terhadap Susut Teknis Pada Industri Semen (Kasus Industri Semen Tonasa). Magister Student of Hasanuddin University. 2010.

[5] Arrillaga, J. and Watson, N. R. Power System Harmonic Analysis. New Zealand. University of Canterbury. 2000.

[6] IEEE Std C57.91-1993. Standard Test Code for Liquid-Immersed Distribution, Power, and Regulating Transformers and Guide for Short-Circuit Testing. 1993.

[7] IEEE Std C57.91-1995. Loading Guide for Mineral Oil Immersed. 1995.

[8] IEEE Std C57.110 ${ }^{\mathrm{TM}}$-2008. Recommended Practice for Establishing Liquid-Filled and Dry-Type Power and Distribution Transformer Capability When Supplying Nonsinusoidal Load Current. 2008.

[9] PT. PLN (Persero). Executive Summary BARA 2016. Bali. 2016.

[10] PERMEN ESDM Nomor : 04 tahun 2009 Aturan Distribusi Tenaga Listrik. Jakarta. 2009. 